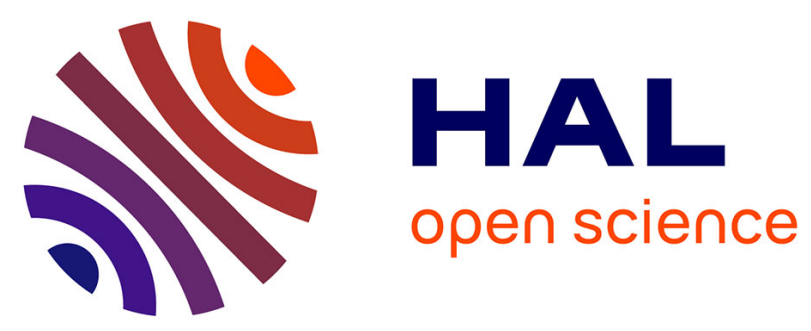

\title{
Product Circularity Assessment Methodology
}

Cecilia Maria Angioletti, Mélanie Despeisse, Roberto Rocca

\section{To cite this version:}

Cecilia Maria Angioletti, Mélanie Despeisse, Roberto Rocca. Product Circularity Assessment Methodology. IFIP International Conference on Advances in Production Management Systems (APMS), Sep 2017, Hamburg, Germany. pp.411-418, 10.1007/978-3-319-66926-7_47 . hal-01707263

\section{HAL Id: hal-01707263 \\ https://hal.inria.fr/hal-01707263}

Submitted on 12 Feb 2018

HAL is a multi-disciplinary open access archive for the deposit and dissemination of scientific research documents, whether they are published or not. The documents may come from teaching and research institutions in France or abroad, or from public or private research centers.
L'archive ouverte pluridisciplinaire HAL, est destinée au dépôt et à la diffusion de documents scientifiques de niveau recherche, publiés ou non, émanant des établissements d'enseignement et de recherche français ou étrangers, des laboratoires publics ou privés. 


\title{
Product Circularity Assessment Methodology
}

\author{
Cecilia Maria Angioletti ${ }^{1}$, Mélanie Despeisse ${ }^{2}$ and Roberto Rocca ${ }^{1}$ \\ ${ }^{1}$ Department of Management, Economics and Industrial Engineering, Politecnico di Milano, \\ 20156 Milan, Italy \\ ceciliamaria.angiolettiepolimi.it \\ roberto.rocca@polimi.it \\ ${ }^{2}$ Industrial and Materials Science, Chalmers University of Technology, 41296 Gothenburg, \\ Sweden \\ Melanie.despeissedchalmers.se
}

\begin{abstract}
In today's dynamic economic environment, industry is facing global challenges such as meeting the needs of a growing population, resource scarcity and landfill space shortage. These issues highlight the need for a dramatically more efficient use of natural resources to create social and economic value for society while respecting the carrying capacity limits of the planet. Additive manufacturing technologies provide opportunities to support sustainable manufacturing and the circular economy paradigm. These opportunities can be leveraged throughout the product lifecycle: energy and material consumption reduction in manufacturing, lower material use through maintenance, reuse, remanufacturing and recycling. Despite these benefits being more broadly recognised in recent years, industrial applications are still scarce. This work proposes a quantitative methodology to assess the circularities arising along the lifecycle of a product fabricated with additive manufacturing technologies, thereby supporting the shift to more circular industrial systems and sustainability.
\end{abstract}

Keywords: Circularity $\cdot$ Assessment methodology $\cdot$ Additive manufacturing

\section{$1 \quad$ Introduction}

\section{$1.1 \quad$ Background}

The digital world is becoming an integral part of industrial systems and of our society, and is enabled by new technological developments such as Additive Manufacturing Technologies (AMT). ASTM international defines Additive Manufacturing (AM) as a fabrication process used to build physical objects, starting from 3D computer-aided design (CAD) file and by adding material layer upon layer until the final object is completely formed [1].

Advances in science and technology contribute to the evolution and betterment of our society, but also result in unintended impacts on natural resources' availability and the surrounding environment. Increasing consumerism and irresponsible use of virgin materials (that lead to natural resource depletion and to dangerous and irreversible environmental damages) affect the economy and society at large. Therefore sustainability 
is an essential prerogative to ensure the stability of economic systems and natural ecosystems within which manufacturing companies need to compete responsibly [2].

Beside technology innovation, recent financial and environmental crises have caught the attention of many world governments. Furthermore, acceleration in global growth and the gap between the world leading and developing countries creates an imbalanced environment for competition. In this context, traditional models for the economic development have proven to be unsustainable and the growth trend characterizing the last century is not feasible anymore.

Industry and society need to change the way it operates by undertaking intelligent and integrated actions to enable long-term development while respecting human values, monitoring of our impact on the ecosystem and sustain economic growth. The circular economy (CE) paradigm has been emerging among other economic philosophies as it pursues the goals of economic, social and environmental sustainability [3].

\subsection{Circular Systems and Circular Economy}

Industrial Ecology (IE) and Industrial Symbiosis (IS) are often associated with the CE philosophy, despite some differences in principles and definitions. The ability to reuse resources and trigger circular flows has a strong analogy with the natural eco-systems as advocated by IE proponents [4]. IS promotes the exchange of waste and by-products from geographically delimited sites, where the contribution to CE stands in the intensive action of co-located manufacturing processes to drain the maximum value from local resources [5]. While IE and IS promote closed loop resource flows with an endof-pipe approach, CE highlights the role of design in drawing end-of-life consideration as a starting point for resource reuse and value retention within the industrial system.

Circular systems provide a value-creation mechanisms decoupled from resources depletion. This can be supported by the creation of a sustainable model able to better capture and maintain the value embedded in resources while avoiding economic loss and environmental impacts on the long term [6]. Flows are dynamic and move in a circular manner in a closed loop (same application) or open loop (for a different application) [6]-[7]. Thus, CE is "a continuous positive development cycle that preserves and enhances natural capital, optimises resource yields, and minimises system risks by managing finite stocks and renewable flows" [8].

Opportunities for circularities might occur at different phases of the product lifecycle. When occurring closer to the consumption point, fewer additional resources and actions are required for recovery and treatment activities to restore the product value.

Therefore, Reuse is the most advantageous scenario as resources or products can be used again without the need for additional resources and circularity is maximized. Maintenance \& Repair enhances the product lifecycle stretching, bringing the product back at his original working conditions by repairing, reconditioning or replacing damaged parts. Recycling aims to recover materials back into the system as crude feedstock and substitute virgin material inputs. This work accounts for material quality and properties as they change through recycling activities [8], and for the economic viability of recycling [9]. Energy Recovery is generally characterized by a waste incineration process from which energy is generated and handed back to the system, lowering the need 
for energy provision. Landfill is the least sustainable scenario as resources leave the economic and industrial system, preventing the chance for further exploitation.

\subsection{Additive Manufacturing and Sustainability}

Current literature highlights the benefits of AM for efficiency and sustainability. Potential savings of $170-593$ billion $\$$ and $\mathrm{CO}_{2}$ emission reduction of $130.5-525.5 \mathrm{Mt}$ by 2025 [10] are estimated based on opportunities for dematerialization and simplified logistics, improvements in parts design intended for better performances in use, new recycling opportunities and landfill avoidance [11]. AM has the potential to reduce virgin materials mining and polluting auxiliary inputs in the production phase and subsequent activities [12]. Faludi et al. propose a LCA comparing the environmental sustainability of AM and CNC, and found that Fused Deposition Modelling (FDM) is more sustainable than CNC [13]. While software and hardware cost are still high, reduction in tooling and lead time from design to production are making AM competitive and cost-effective [14]. Baumers et al. also performed a cost assessment of AM use and determined that, despite economies of scale still applying for AM, machine cost has the highest impact on the overall cost [15]. Further benefits might come for the product lifecycle stretching by means of reuse, repair and remanufacturing, together with new business model opportunities, shorten and high-value supply chains, lowering in production volumes and stocks due to customization [16]. Despite the chances for AM in terms of CE, further work is required to address this topic.

Apart from Ellen MacArthur Foundation's proposal of performance indicators specifically intended to capture the impact of the design phase on the ability to reduce waste and sustain circularity [8], it is mainly about adapting ecology and sustainable assessments together with cost-driven tools to CE purposes. Starting from a lifecycle perspective and resources flows analysis, the next sections are intended to propose a methodology to assess products' ability in triggering circularity.

\section{$2 \quad$ Product Circularity Assessment (CPA) Methodology}

This section describes the CPA methodology, a quantitative tool intended to capture and quantify the amount of circular flows occurring along the product lifecycle. The expected outcome is the circularity product indicator (CPI), a percentage value intended to capture the product performances in terms of circularity.

\subsection{CPA Methodology Principles}

While the CPA methodology is not sector- or technology-specific, it is adaptable and flexible to a broad range of applications. It accounts for various types of circular flows based on four principles:

1. Use less: reduced resource requirements for a given useful output (i.e. thermodynamic efficiency and eco-efficiency), enabling a reduction of mining activities and impacts deriving from treatments, consumption and disposal activities. 
2. Absorb circularities: use of recycled materials, reuse and energy recovery intended to reduce the need for virgin materials to be processed and energy to be provisioned.

3. Generate circularities: opportunity generated from the product-system for material to be reused, recycled and for waste to undergo the energy recovery.

4. Use of renewable energy sources: renewable resources can be used at a sustainable rate, if exploitation does not exceed regeneration rate.

Circular flows cannot be categorized a priori as generated or absorbed, but depending on the resource flow history. Absorption of resource flows coming from within the product-system itself or from other systems is counted when defining the CPI. Circular flows generated by the product-system and re-entering the system as absorbed circularities are neglected, as to avoid to double counting. Finally, generated circularities for external systems are not accounted at this stage of development of the methodology.

The circular flows are evaluated as the ability to reduce the use of energy, materials or auxiliary resources along the product's lifecycle compared to more traditional alternatives where circularities are not exploited. The circularity scenarios and traditional alternatives are listed in table 1 . Note that landfill does not have a circular scenario as the product or resource permanently leaves the system.

Table 1. Circularity scenarios compared to traditional alternatives.

\begin{tabular}{|c|l|}
\hline Circularity & \multicolumn{1}{|c|}{ Traditional alternatives } \\
\hline Reuse & $\begin{array}{l}\text { Manufacture (and all upstream related activities and resources usage) of a } \\
\text { new product/component }\end{array}$ \\
\hline $\begin{array}{c}\text { Maintenance \& } \\
\text { Repair }\end{array}$ & $\begin{array}{l}\text { Manufacture (and all upstream related activities and resources usage) of a } \\
\text { new product/component }\end{array}$ \\
\hline Recycling & $\begin{array}{l}\text { New raw material extraction, treatments and related activities (including } \\
\text { resources usage) }\end{array}$ \\
\hline Energy Recovery & New energy production and related activities (including resources usage) \\
\hline
\end{tabular}

\subsection{CPA Steps}

The proposed CPA methodology is designed in four steps:

CPA Step 1: Objectives and System Boundaries. The functional unit is the product or component considered for the assessment. Electricity, thermal energy, materials and other auxiliary resources embody the reference flows. The methodology follows a "cradle to cradle" approach and the boundaries of analysis account for inter-systemic exchanges, relying on an open-system frame.

CPA Step 2: Inventory Analysis. System mapping and data specification provide a detailed description of the product-system analysed, the related processes and the resource flows. Then, the inventory analysis is performed and data gathered include power consumption $[\mathrm{Wh}]$ and resource quantities $[\mathrm{kg}]$.

CPA Step 3: Resource Circularity Indicators. Following the circularity principles abovementioned and the opportunities for circularity at different stages of the product lifecycle, the circularity indicators for materials $\left(M C I_{m, p}\right)$ and auxiliary resources 
$\left(R C I_{r, p}\right)$ are calculated for each process step $p$ and respectively for each material $e$ or auxiliary resource $r$. The circularity indicator for energy $\left(E C I_{p}\right)$ is addressed for each process but are not detailed at material or auxiliary resource level as power requirements and consumptions are usually monitored at machine/process level. Then, the circularity indicators are aggregated to obtain overall product-system level circularity indicators for energy (ECI), materials (MCI) and auxiliary resources (RCI).

CPA Step 4: Product Circularity Indicator. The last step consists of the CPI calculation as geometrical combination of ECI, MCI and RCI:

$$
C P I=\frac{K}{\sqrt{3}}=\frac{\sqrt{E C I^{2}+M C I^{2}+R C I^{2}}}{\sqrt{3}} * 100
$$

where $0 \leq \mathrm{CPI} \leq 1$, and

$$
K^{2}=E C I^{2}+M C I^{2}+R C I^{2}
$$

In this research, all three variables are considered to have an equal impact on efficiency and sustainability as the relative importance of each type of resource is specific to individual companies. Therefore, weight can be assigned to energy, materials and auxiliary resources based on specific industrial sectors, regulations, incentives, market or supply-chain structure (e.g. risk or difficulties in the supply of specific resources), material (e.g. physical requirements guaranteed by virgin materials only), etc.

The CPI is expected to range from 0 to 1 . If ECI, MCI and RCI are all equal to zero, then the CPI will have a null value, meaning that the product-system is purely linear with no resource recovery and no renewable sources. On the contrary, a CPI value equal to 1 is the ideal scenario where all resources involved in the product-system originate from and generate circular flows.

\section{Short Application and Results}

The CPA methodology is applied to a simplified case study of a mono-material biomedical product fabricated by Direct Metal Laser Sintering (DLMS) technology (EOSINT M270 machine). The data available on material and energy are used to quantify the CPI of a metal $(\mathrm{CoCr})$ dental crown which is the functional unit of analysis. The product-system is characterized by four processes as follow: (i) atomization, (ii) production, (iii) sandblasting, (iv) heat treatment. For this simplified lifecycle assessment, material processing (metals mining and forming) is neglected, together with the creation of ingots used in atomization. Due to some gaps in the data available, data from literature and estimations along with data supplied by the company were used for this analysis, even if limited to the production steps. The lack of experimental data related to the product use and maintenance phases, this application is limited to the production processes. It is assumed that the product cannot be recycled, but landfilled at its endof-life. The volume and mass values of dental crowns are shown in table 2. 
Table 2. Material volume and mass of a dental crown.

\begin{tabular}{|c|c|c|}
\hline Dental crown & Sacrificial structures & Total \\
\hline $50.889 \mathrm{~mm} 3$ & $28.373 \mathrm{~mm} 3$ & $79.262 \mathrm{~mm} 3$ \\
\hline $0.443 \mathrm{~g}(54 \%)$ & $0.247 \mathrm{~g}(46 \%)$ & $0.69 \mathrm{~g}(100 \%)$ \\
\hline
\end{tabular}

(i) Atomization. Powder formation is one key factor for resource consumption as it affects both the potential for dematerialization and the reduction of energy usage within the production phase.

(ii) Production. DMLS technique relies on a powder bed fusion process. Such metal AM processes often require post-processing for supports removal and surface finishing, depending on powder grains size, which is usually energy intensive.

(iii) Sandblasting. The dental crowns are mechanically treated by corundum (aluminium oxide) to clean the metal surface from leftovers and corrosive deposits.

(iv) Heat Treatment. Once blasted, the platform enters the furnace for the thermal treatment to release internal stresses. This is an energy intensive process which significantly impacts the overall efficiency and circularity of the product-system.

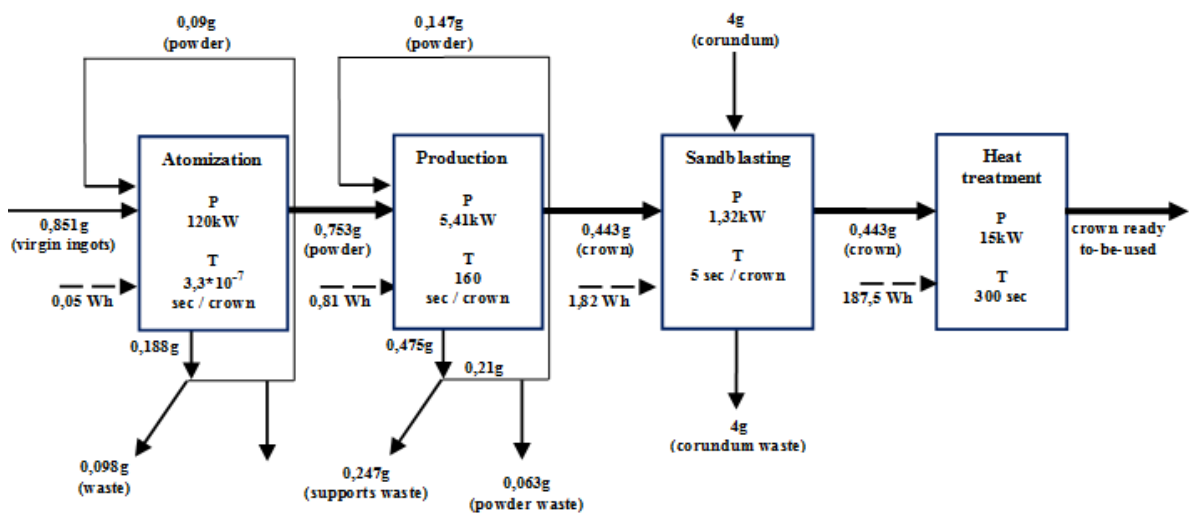

Fig. 1. Product-system characterization and resource flow mapping where $P$ the nominal power and $\mathrm{T}$ the processing time for each process.

Figure 1 schematizes the flows within product-system pinpointing the opportunities for circular flows to occur. Thus, circularities are quantified to determine the ECI and MCI at system level. From the available data it comes to ECI $=33,20 \%$ and $\mathrm{MCI}=20,10 \%$. Thus, $\mathrm{CPI}=22,41 \%$ meaning that about a fifth of the resources used to produce the dental crowns are originating from or generating circular flows.

Energy has high impact on products' circularity (non-renewable energy sources). This case study excludes the ingots formation which is an energy intensive activity, and the thermal power as it does not significantly to influence the system's energy consumption. The material waste cannot undergo energy recovery and generate a positive impact on energy circularity. Materials' circularity is mainly linked to the possibility for atomization and production phase to recover powders from downstream and replace 
virgin feedstock. It is estimated that ingots fabrication could enhance material circularity as it is an efficient process. Due to the product's characteristics, it is not possible to account for a different EoL scenario from landfill. Finally, $\mathrm{CoCr}$ is produced from nonrenewable resources and is currently not recycled. In order to create opportunities for non-virgin inputs of material, recycling of the supports and EoL products, further development of recycling technologies is required.

\section{Conclusions}

Technological and societal advancements have triggered innovations and development while causing undesirable consequences such as natural resources depletion, waste generation and damages to the natural ecosystem. It is clear that we need a more sustainable economic and industrial model. The CE paradigm along with IE concepts respond to these needs with the aim to maximize economic, environmental and social value created from industrial activities. Among other advanced technologies, AM holds the potential to trigger circularities through dematerialization, manufacturing systems reconfigurations, extended product lifecycle, etc. generating economic and environmental benefits.

This paper proposes an assessment methodology to quantify the circularity of a product by a simplified lifecycle perspective and accounting for inter-systemic exchanges of resources. The methodology outcome is the circularity product indicator (CPI) which represents the percentage value of circular flows along the product lifecycle. In other word, it is the ability of the product to reduce natural resource consumption and waste generation along its lifecycle compared to more traditional alternatives in which circularities are not exploited. This paper presents an application example of the methodology using a simple mono-material biomedical product to assess the potentials of circularities created through the use of AM. The results show that the use of renewable energy sources together with the characteristics of the production process positively affect the ECI value. As expected, powder recovery and reuse without further treatment or resources addition can improve the MCI. The overall CPI revealed that about a fifth of the resources used to produce the product are originating from or generating circular flows. This result would need consolidation by expanding the scope of the assessment to the full product's lifecycle. However, this could not be achieved due to data availability issues and thus the assessment focus on the production stage only.

Future research is needed to test the methodology on more complex products such as multi-material, multi-component products where more circularity opportunities arise (e.g. product life extension through the repair, remanufacturing and upgrades). Moreover, CPA improvements should account for the generation of circular flows absorbed outside the system boundaries (i.e. open-loop recycling of the waste and by-product of the product system considered). A more advanced application should be conducted to show the wider impact of product circularity on the overall sustainability performance of manufacturing systems. 


\section{References}

[1] W. E. Frazier, "Metal additive manufacturing: A review," J. Mater. Eng. Perform., vol. 23, no. 6, pp. 1917-1928, 2014.

[2] J. Elington, Cannibals with forks: The triple bottom line of 21 st century business. Capstone publishing, Oxford, 1999.

[3] Ellen MacArthur Foundation, "Towards a circular economy: Business rationale for an accelerated transitions," 2015.

[4] R. U. Ayres and L. W. Ayres, A Handbook of Industrial Ecology. Cheltenham, UK Northampton MA, USA: Edward Elgar Publishing, 2002.

[5] G. T. Renner, "Geography of industrial localization," Econ. Geogr., vol. 3, no. 3, pp. 167189, 1947.

[6] Ellen MacArthur Foundation, "Economic and business rationale for an accelerated transition," 2012.

[7] S. Hashimoto and Y. Moriguchi, "Proposal of six indicators of material cycles for describing society's metabolism: From the viewpoint of material flow analysis," Resour. Conserv. Recycl., vol. 40, no. 3, pp. 185-200, 2004.

[8] Ellen MacArthur Foundation, "Circularity Indicators. An Approach to Measuring Circularity," 2015.

[9] G. Villalba, M. Segarra, A. I. Fernández, J. M. Chimenos, and F. Espiell, “A proposal for quantifying the recyclability of materials," Resour. Conserv. Recycl., vol. 37, no. 1, pp. 3953, 2002.

[10] M. Gebler, A. J. M. Schoot Uiterkamp, and C. Visser, "A global sustainability perspective on 3D printing technologies,” Energy Policy, vol. 74, no. C, pp. 158-167, 2014.

[11] M. Baumers, C. Tuck, R. Hague, I. Ashcroft, and R. Wildman, "A comparative study of metallic additive manufacturing power consumption," in Solid Freeform Fabrication Symposium, 2010, no. 2009, pp. 278-288.

[12] S. H. Huang, P. Liu, A. Mokasdar, and L. Hou, "Additive manufacturing and its societal impact: A literature review," Int. J. Adv. Manuf. Technol., vol. 67, no. 5-8, pp. 1191-1203, 2013.

[13] J. Faludi, C. Bayley, S. Bhogal, and M. Iribarne, "Comparing environmental impacts of additive manufacturing vs traditional machining via life-cycle assessment," Rapid Prototyp. J., vol. 21, no. 1, pp. 14-33, 2015.

[14] E. Atzeni et al., "Additive manufacturing as a cost-effective way to produce metal parts," in High Value Manufacturing: Advanced Research in Virtual and Rapid Prototyping Proceedings of the 6th International Conference on Advanced Research and Rapid Prototyping,VR@P 2013, 2014, pp. 3-8.

[15] M. Baumers, P. Dickens, C. Tuck, and R. Hague, "The cost of additive manufacturing: Machine productivity, economies of scale and technology-push," Technol. Forecast. Soc. Change, vol. 102, pp. 193-201, 2016.

[16] S. Ford and M. Despeisse, "Additive manufacturing and sustainability: an exploratory study of the advantages and challenges," J. Clean. Prod., vol. 137, pp. 1573-1587, 2016. 